\title{
Fitness costs restrict niche expansion by generalist niche-constructing pathogens
}

\author{
Julien Lang ${ }^{1,3,4}$, Armelle Vigouroux ${ }^{1,3}$, Abbas El Sahili ${ }^{1,5}$, Anthony Kwasiborski ${ }^{1,6}$, \\ Magali Aumont-Nicaise ${ }^{1}$, Yves Dessaux ${ }^{1}$, Jacqui Anne Shykoff ${ }^{2}$, Solange Moréra ${ }^{1}$ \\ and Denis Faure ${ }^{1}$ \\ ${ }^{1}$ Institute for Integrative Biology of the Cell (I2BC), CNRS CEA Université Paris-Sud, Université Paris-Saclay, \\ Gif-sur-Yvette, France and ${ }^{2}$ Ecologie Systématique Evolution, CNRS, Université Paris-Sud, AgroParisTech, \\ Université Paris-Saclay, Orsay, France
}

\begin{abstract}
We investigated the molecular and ecological mechanisms involved in niche expansion, or generalism, versus specialization in sympatric plant pathogens. Nopaline-type and octopine-type Agrobacterium tumefaciens engineer distinct niches in their plant hosts that provide different nutrients: nopaline or octopine, respectively. Previous studies revealed that nopaline-type pathogens may expand their niche to also assimilate octopine in the presence of nopaline, but consequences of this phenomenon on pathogen dynamics in planta were not known. Here, we provided molecular insight into how the transport protein NocT can bind octopine as well as nopaline, contributing to niche expansion. We further showed that despite the ability for niche expansion, nopaline-type pathogens had no competitive advantage over octopine-type pathogens in co-infected plants. We also demonstrated that a single nucleotide polymorphism in the nocR gene was sufficient to allow octopine assimilation by nopaline-type strains even in absence of nopaline. The evolved nocR bacteria had higher fitness than their ancestor in octopine-rich transgenic plants but lower fitness in tumors induced by octopine-type pathogens. Overall, this work elucidates the specialization of A. tumefaciens to particular opine niches and explains why generalists do not always spread despite the advantage associated with broader nutritional niches.
\end{abstract}

The ISME Journal (2017) 11, 374-385; doi:10.1038/ismej.2016.137; published online 1 November 2016

\section{Introduction}

Niche construction designates the process by which a living population modifies its environment and takes advantage of the induced environmental changes (Kylafis and Loreau, 2011). Niche construction processes help explain how sympatric populations can reduce direct competition when coexisting in the same habitat, when each is able to construct and retrieve benefits from its particular niche. However, the resulting equilibrium might be threatened if a population can also exploit niches that are

Correspondence: D Faure or S Moréra, Centre National de la Recherche Scientifique, Avenue de la Terrasse, Gif-sur-Yvette 91 198, France.

E-mail: denis.faure@i2bc.paris-saclay.fr or solange.morera@i2bc. paris-saclay.fr

${ }^{3}$ These authors contributed equally to this work.

${ }^{4}$ Current address: IPS2, INRA, Gif-sur-Yvette 91 190, France.

${ }^{5}$ Current address: Division of Structural Biology \& Biochemistry ।

Nanyang Technological University Proteos, Singapore 138673 Singapore.

${ }^{6}$ Current address: Institut de Recherche en Horticulture et Semences, UMR 1345 INRA-Université d'Angers-Agrocampus Ouest, 42 Rue Georges Morel-CS 60057, 49071 Beaucouzé Cedex, France.

Received 28 March 2016; revised 4 August 2016; accepted 7 September 2016; published online 1 November 2016 constructed by others, a feature referred to as niche expansion that corresponds to an evolution towards a more generalist ecological behavior. Indeed generalist strategies appear to have an advantage in fine-grained environments where individuals may encounter different habitat types or nutritional niches. The existence of several specialists instead of a single generalist is therefore an evolutionary and ecological puzzle that remains unsolved despite long and active debates (Futuyama and Moreno, 1988; Palaima, 2007). All models that explore the conditions for the evolution and coexistence of specialists and generalists (for example, Wilson and Yoshimura, 1994; Egas et al., 2004; Abrams, 2006, 2012; Nurmi and Parvinen, 2008) assume that generalists trade off their ability to exploit multiple niches for their efficiency in any one. Indeed, were there no cost to being a generalist, generalists would always replace specialists, so the coexistence of these two strategies requires the existence of such costs, which are, however, seldom evaluated (Kassen, 2002; Palaima, 2007; Satterwhite and Cooper, 2015; Schick et al., 2015). Here, work with the plant pathogen Agrobacterium tumefaciens permits us to contribute new observations that help elucidate these questions of the evolution of generalist versus specialist strategies 
and competition and coexistence of the two types of strategies within their constructed niches.

The plant pathogen Agrobacterium tumefaciens is remarkable in its ability to generate specific nutrient niches in its host plants. On infection, $A$. tumefaciens transfers a DNA-fragment (namely the T-DNA) from the tumor-inducing (Ti) plasmid into the plant host cells (Pitzschke and Hirt, 2010). Once integrated into the plant host nuclear genome, the T-DNA genes drive niche construction by producing a tumor within which low molecular weight $\left(200-600 \mathrm{~g} \mathrm{~mol}^{-1}\right) \mathrm{com}$ pounds, called opines, are synthesized. Only A. tumefaciens cells that contain a Ti-plasmid can catabolize opines, which are thus key players in Agrobacterium niche construction (Guyon et al., 1980; Tempé and Petit, 1983). Indeed, bacterial cells harboring Ti-plasmids that catabolize opines outcompete cells with mutant Ti-plasmids lacking opine catabolic activity, formally demonstrating the opineniche concept (Lang et al., 2014). Importantly, as different Ti-plasmids code and catabolize opines with a range of molecular structures (over twenty different opines described; (Dessaux et al., 1998), there may be several distinct opine niches in plant tumors, allowing the coexistence of different $A$. tumefaciens populations (Tempé and Petit, 1983; Bouzar and Moore, 1987).

Nopaline and octopine are among the most extensively studied opines: nopaline is a condensate of arginine and $\alpha$-ketoglutarate, whereas octopine is a condensate of arginine and pyruvate (Dessaux et al., 1992, 1998). The nopaline-type $A$. tumefaciens strains construct a nopaline niche and assimilate nopaline, whereas the octopine-type $A$. tumefaciens strains construct an octopine niche and assimilate octopine. Thus, these two pathogen populations should be able to co-exist in distinct niches in the same plant tumor. However, early works revealed that the nopaline assimilative pathway also permits the importation and degradation of octopine (Klapwijk et al., 1977; Zanker et al., 1992, 1994). Hence, nopaline-type strains are able to assimilate octopine once nopaline induces the nopaline assimilative pathway, giving them the ability to expand their nutritional niche, potentially competing with octopine-strains and changing the conditions for stable coexistence.

Combining structural biology, molecular microbial ecology and plant genetics, we explored A. tumefaciens niche construction and exploitation, testing for niche expansion and competition. Our results help explain how different $A$. tumefaciens opine types can persistently co-exist in the same host plant and even in the same tumor, despite the apparent ability of some A. tumefaciens pathogens to exploit more than one opine-niche.

\section{Materials and methods}

Synthesis, detection and quantification of opines Nopaline was synthetically obtained by condensation between L-arginine and $\alpha$-ketoglutarate in the presence of sodium cyanoborohydride as described by Tempé (1983). Octopine was synthetically obtained by condensation between L-arginine and L2-bromopropionic acid (Tempé, 1983). The detection and quantification of opines in whole extracts of plant tumors was done following a separation of compounds by high-voltage paper electrophoresis and chemical revelation using the phenanthrene quinone reagent (Dessaux et al., 1992).

\section{Purification, crystallization and structure determination of NocT and its M117N mutant in complex with octopine}

The NocT protein of the nopaline-type $A$. tumefaciens C58 and NocT-M117N mutant were purified and co-crystallized with octopine instead of nopaline as previously described (Lang et al., 2014). High resolution diffraction data were collected at $100 \mathrm{~K}$ on the PROXIMA I beamline at SOLEIL synchrotron (Saint-Aubin, France). Data collection and processing statistics are given in Supplementary Table S1. Because the crystals of NocT and M117N mutant with octopine are isomorphous to those with nopaline, phase determination was straightforward. The resulting electron density maps showed the presence of an octopine in the ligand binding site. Refinement was performed with BUSTER-2.10 (Blanc et al., 2004) with non crystallographic symmetry restraints as all asymmetric units contain two protein molecules. One torsion libration screw-motion group was assigned for each structure. Electron density maps were evaluated using COOT (Emsley and Cowtan, 2004). Refinement details are shown in Supplementary Table S1. Molecular graphics images were generated using PYMOL software (http://www. pymol.org).

\section{$K_{D}$ measurements by fluorescence titration and microcalorimetry}

Octopine bound to NocT was monitored by autofluorescence by exciting the protein at a wavelength of $295 \mathrm{~nm}$ and monitoring the quenching of fluorescence emission of tryptophan residues at $335 \mathrm{~nm}$. The experiment was performed at $22^{\circ} \mathrm{C}$ in $3 \times 15 \mathrm{~mm}$ quartz cuvettes using a Cary Eclypse spectrofluorometer (Varian, AgilentTechnologies, Santa Clara, CA, USA), in $25 \mathrm{~mm}$ Tris-HCl pH 8 and $150 \mathrm{~mm} \mathrm{NaCl}$ with a fixed amount of proteins $(2 \mu \mathrm{M})$ and increasing concentrations of octopine. Each ligand had no emission signal at $335 \mathrm{~nm}$. The data were analysed using Origin 7 software (OriginLab Corp., Northampton, MA, USA) and fitted to the equation $f=\Delta$ Fluorescencemax ${ }^{*} \operatorname{abs}(\mathrm{x}) /\left(K_{\mathrm{D}}+\mathrm{abs}(\mathrm{x})\right)$.

Isothermal titration microcalorimetry experiments were performed with an ITC200 isothermal titration calorimeter from MicroCal (GE Healthcare, Uppsala, Sweden). The experiments were carried out at $20^{\circ} \mathrm{C}$. Protein concentration in the microcalorimeter cell $(0.2 \mathrm{ml})$ was $100 \mu \mathrm{M}$. Nineteen injections of $2 \mu \mathrm{l}$ of 
octopine solution at $1 \mathrm{~mm}$ were performed at $180 \mathrm{~s}$ intervals while stirring at 1000 r.p.m. The experimental data were fitted to theoretical titration curves with the software supplied by MicroCal (ORIGIN). This software uses the relationship between the heat generated by each injection and $\Delta H$ (enthalpy change in $\mathrm{Kcal} \mathrm{Mol}^{-1}$ ), $\mathrm{Ka}$ (the association binding constant in $\mathrm{M}^{-1}$ ), $n$ (the number of binding sites), total protein concentration and free and total ligand concentrations.

\section{Bacterial strains and growth conditions}

The octopine-type A. tumefaciens strain R10 and nopaline-type $A$. tumefaciens strain C58 were from our laboratory collection. A. tumefaciens C58 derivatives carrying mutations in the Ti-plasmid had been previously constructed. They were: (i) C58 (pTi::Gm), that carries a gentamycin (Gm) cassette inserted into the atu6147 gene, which is not involved in virulence, fitness in plant tumor or opine pathways (Haudecoeur et al., 2009; Lang et al., 2013); (ii) C58 (pTi-nos::Km) that carries a kanamycin (Km) cassette inserted into the nos gene (=atu6015), which is involved in the T-DNA-directed, nopaline synthesis in host plant; and, (iii) C58 (pTi-ocd::Gm) that contains a $\mathrm{Gm}$ resistance cassette inserted into the ocd gene (=atu6016), which is involved in nopaline catabolism (Lang et al., 2014). We imposed artificial selection for modified opine assimilation as follows: to select for octopine assimilation ability in nopaline-type strains, overnight liquid cultures of nopaline-type A. tumefaciens C58 (pTi::Gm) and C58 (pTi-nos::Km) were washed three times, adjusted to $\mathrm{OD}_{600 \mathrm{~nm}}=1$ and $3 \mathrm{ml}$ of these cultures were plated onto agar AB medium (Chilton et al., 1974) containing $3 \mathrm{~mm}$ of octopine as sole source of carbon and nitrogen and incubated for 5 days. Similarly, the octopine-type $A$. tumefaciens R10 was cultivated with nopaline as a sole nutrient source. Characteristics of the $A$. tumefaciens strains used in this study are summarized in the Table 1. A. tumefaciens was cultivated at $30^{\circ} \mathrm{C}$ in Agrobacterium broth (AB) minimal medium supplemented with ammonium chloride $\left(1 \mathrm{~g} \mathrm{l}^{-1}\right)$ and mannitol $\left(2 \mathrm{~g} \mathrm{l}^{-1}\right)$ except when an alternative source of carbon and nitrogen is indicated, or in Luria-Bertani modified medium (LBm, with $5 \mathrm{~g} \mathrm{l}^{-1} \mathrm{NaCl}$ ). The antibiotics gentamycin and kanamycin were added at $25 \mu \mathrm{g} \mathrm{ml}^{-1}$ and $100 \mu \mathrm{g} \mathrm{ml}^{-1}$, respectively.

\section{DNA extraction, genome sequencing and variant analysis}

DNA was extracted and purified with the DNeasy Blood and Tissue kit (Qiagen, Les Ulis, France) according to the manufacturer's instructions. For each clone, paired-end libraries $(2 \times 100)$ were prepared from $5 \mu \mathrm{g}$ of total genomic DNA using the TruSeq SBS Kit v3-HS 200-cycles (FC-401-3001, Illumina, Paris, France). Hiseq sequencing was performed at the Imagif platform (Gif-sur-Yvette, France) and the data were analyzed through the CASAVA-1.8.2 (Illumina; demultiplexing), Fastqc 0.10.1 (Babraham, UK; read quality) and Cutadapt1.3 (Wilmington, DE, USA; adapter trimming) pipeline. Sequence reads were mapped on the annotated reference genome of $A$. tumefaciens strain C58 (Wood et al., 2001). Mappings were carried out using the CLC Genomics Workbench v7.5 (CLC bio, Aarhus, Denmark) with a read length \#0.9 and similarity \#0.95. Genomic variant detection was processed using CLC Genomics Workbench with a minimum coverage of 10 and a variant probability of $90 \%$.

RNA extraction and gene expression analysis Total bacterial RNA was extracted from early exponential phase cells using phenol-based protocol as previously described (Lang et al., 2013). cDNA was prepared from $1 \mu \mathrm{g}$ of RNA using RevertAid $\mathrm{H}$ Minus First Strand cDNA Synthesis Kit (Fermentas, Villebon, France) following the manufacturer's instructions. Quantitative reverse transcription polymerase chain reactions (RT-qPCRs) were performed

Table 1 Bacterial strains

\begin{tabular}{|c|c|c|}
\hline strain & Relevant genotype and property & $\begin{array}{l}\text { Source or } \\
\text { reference }\end{array}$ \\
\hline A. tumefaciens R10 & WT, octopine-user & $\begin{array}{l}\text { Laboratory } \\
\text { collection }\end{array}$ \\
\hline A. tumefaciens C58 & WT, nopaline-user & $\begin{array}{l}\text { Laboratory } \\
\text { collection }\end{array}$ \\
\hline A. tumefaciens C58 (pTi::Gm) & $\begin{array}{l}\text { A. tumefaciens C58 derivative, atu6148::acc1, } \mathrm{Gm}^{\mathrm{r}} \text {, unafected for nopaline } \\
\text { synthesis and assimilation }\end{array}$ & $\begin{array}{l}\text { Haudecoeur } \\
\text { et al. (2009) }\end{array}$ \\
\hline A. tumefaciens C58 (pTi-nos::Km) & $\begin{array}{l}\text { A. tumefaciens C58 derivative, nos:: aph } A, \mathrm{Km}^{\mathrm{r}} \text {, defective for nopaline synthesis, } \\
\text { unaffected for nopaline assimilation }\end{array}$ & Lang et al. (2014) \\
\hline A. tumefaciens C58 (pTi-ocd::Km) & $\begin{array}{l}\text { A. tumefaciens C58 derivative, ocd::acc1, } \mathrm{Gm}^{\mathrm{r}} \text {, unaffected for nopaline synthesis, } \\
\text { impaired in nopaline assimilation }\end{array}$ & Lang et al. (2014) \\
\hline Oct+1 to Oct+11 & A. tumefaciens C58 (pTi::Gm) derivatives, $\mathrm{Gm}^{\mathrm{r}}$, constitutive octopine-users & This study \\
\hline Oct +12 to Oct +20 & A. tumefaciens C58 (pTi-nos::Km) derivatives, $\mathrm{Km}^{\mathrm{r}}$, constitutive octopine-users & This study \\
\hline
\end{tabular}


in a Lightcycler 480 II (Roche, Meylan, France) apparatus. The data were processed using the 2$\Delta \Delta \mathrm{CT}$ method. For all primer sets the similarities of amplification efficiencies were controlled. The internal control used was the gene atu2422.

\section{Plant lines, plant infection and quantifying bacterial populations}

All Arabidopsis thaliana plants in this study are from the Columbia ecotype. The OCT+ plant line that accumulates octopine was obtained by inserting the A. tumefaciens octopine synthase gene under the control of a constitutive promoter into the A. thaliana genome as previously described (Mondy et al., 2014). Plants were grown in a greenhouse under long day conditions and controlled temperature $\left(24-26^{\circ} \mathrm{C}\right)$ for three weeks and then transferred into controlled environment chambers $\left(22^{\circ} \mathrm{C}, 8 \mathrm{~h}\right.$ photoperiod, $65 \%$ hygrometry). Young primary stems (about one-month old plants) were wounded with a needle and inoculated with agrobacteria as previously described (Lang et al., 2013), which yielded a single tumor per plant. Crushed tumors at 32 days post-infection were suspended into $0.8 \% \mathrm{NaCl}$ to recover the bacteria. Dilution series were prepared and spread onto selective agar media for enumerating colony forming units (CFU). Selection was based either on antibiotic resistance or on ability to use nopaline/octopine as sole sources of $\mathrm{C}$ and $\mathrm{N}$. For mixed inoculations, an inoculum mix, consisting in equal proportions of the two or three strains, was plated onto non-selective medium. The ratios of the different strains were estimated according to their distinctive phenotype and genotype. The proportions of the different bacterial genotypes were estimated by pooling counts from three independent samples of each mixed inoculum $\left({ }_{\mathrm{P}_{\mathrm{i}}}\right)$ and from a sample of bacteria from each plant tumor $\left(\mathrm{P}_{\mathrm{t}}\right)$. This allowed calculation of the competitive index $\mathrm{CI}=\left(\mathrm{P}_{\mathrm{t}}^{\text {mutant }} / \mathrm{P}_{\mathrm{t}}^{\text {control }}\right) /\left(\mathrm{Pi}_{\mathrm{Pi}}^{\text {mutant }} / \mathrm{Pi}\right.$ control $)$ as previously described (Macho et al., 2010).

\section{Accession codes}

Coordinates and structure factors were deposited at the Protein Data Bank (PDB) under accession code 5ITP for NocT-octopine and 5ITO for NocT-M117N-octopine.

\section{Results}

The nopaline-type pathogen assimilated octopine in the presence of nopaline

The two pathogens A. tumefaciens C58 (nopalinetype) and R10 (octopine-type) assimilated in vitro the opines whose synthesis they induce in the host plants (Figure 1a). Furthermore, we observed that the nopaline-type strain could also metabolize octopine in the presence of nopaline (Figure 1a). Using the A. tumefaciens C58 ocd mutant whose nopaline catabolism is reduced because its arginine assimilation is impaired (Sans et al., 1987; Lang et al., 2014), we were able to infer the involvement of the nopaline catabolic genes in the growth capacity conferred by octopine (Figure 1a). From these data and previous studies (Klapwijk et al., 1977; Zanker et al., 1992), it appeared that $A$. tumefaciens C58 assimilates octopine via the nopaline catabolism pathway, the expression of which is only activated by nopaline. The main molecular actors of opineniche construction and utilization by the nopalinetype and octopine-type $A$. tumefaciens pathogens are presented in Figure 1b.

The octopine- and nopaline-type A. tumefaciens coexisted in the plant tumor

Wild-type $A$. thaliana plants were infected with a mixed inoculum of approximately 1:1 nopaline-type A. tumefaciens C58 and octopine-type A. tumefaciens R10. The plant tumor niches were analyzed 32 days post-infection. Opine quantification revealed that both nopaline $\left(200 \mathrm{pmol} \mathrm{mg}^{-1}\right.$ fresh plant tissues) and octopine $\left(50 \mathrm{pmol} \mathrm{mg}^{-1}\right.$ fresh plant tissues) accumulated in each plant tumor. In these same plant tumors, the total $A$. tumefaciens population reached a mean $\left( \pm\right.$ s.d.) of $2.07 \times 10^{6} \pm 1.54 \times 10^{6}$ $\mathrm{CFU} \mathrm{mg}^{-1}$ fresh plant tissues, and the strain ratio did not differ significantly from that of the inoculum (Fisher's exact test, $P=0.08$ ). This indicated that the two A. tumefaciens opine types, which constructed two different opine niches, co-existed in each plant tumor. Furthermore, though A. tumefaciens C58 can also assimilate octopine in the presence of nopaline, it did not outcompete $A$. tumefaciens strain R10, which only assimilates octopine. In fact, the proportion of the generalist C58 had somewhat, albeit nonsignificantly, decreased from inoculum to tumors. Thus the generalist phenotype, able to assimilate and catabolize both nopaline and octopine, appeared to have no advantage over the specialist octopine-type that benefits from a more restrictive nutritional niche under these conditions.

The import system of nopaline accommodates both nopaline and octopine

The periplasmic nopaline-binding protein NocT is an essential molecular actor in the recognition and uptake of nopaline (Lang et al., 2014; Figure 1b). We investigated, at the atomic level, the binding mode and the specificity of NocT towards nopaline and octopine. We solved the X-ray structure of the NocT in complex with octopine at $1.85 \AA$ resolution. Crystals of NocT in complex with nopaline or octopine are isomorphous and contained two very similar molecules in the asymmetric unit. All liganded NocT structures with nopaline and octopine are also very similar with an overall root mean square deviation for all C $\alpha$ atoms between $0.2 \AA$ and $0.4 \AA$. The octopine located at the interface between the two closed lobes are very well defined in its 


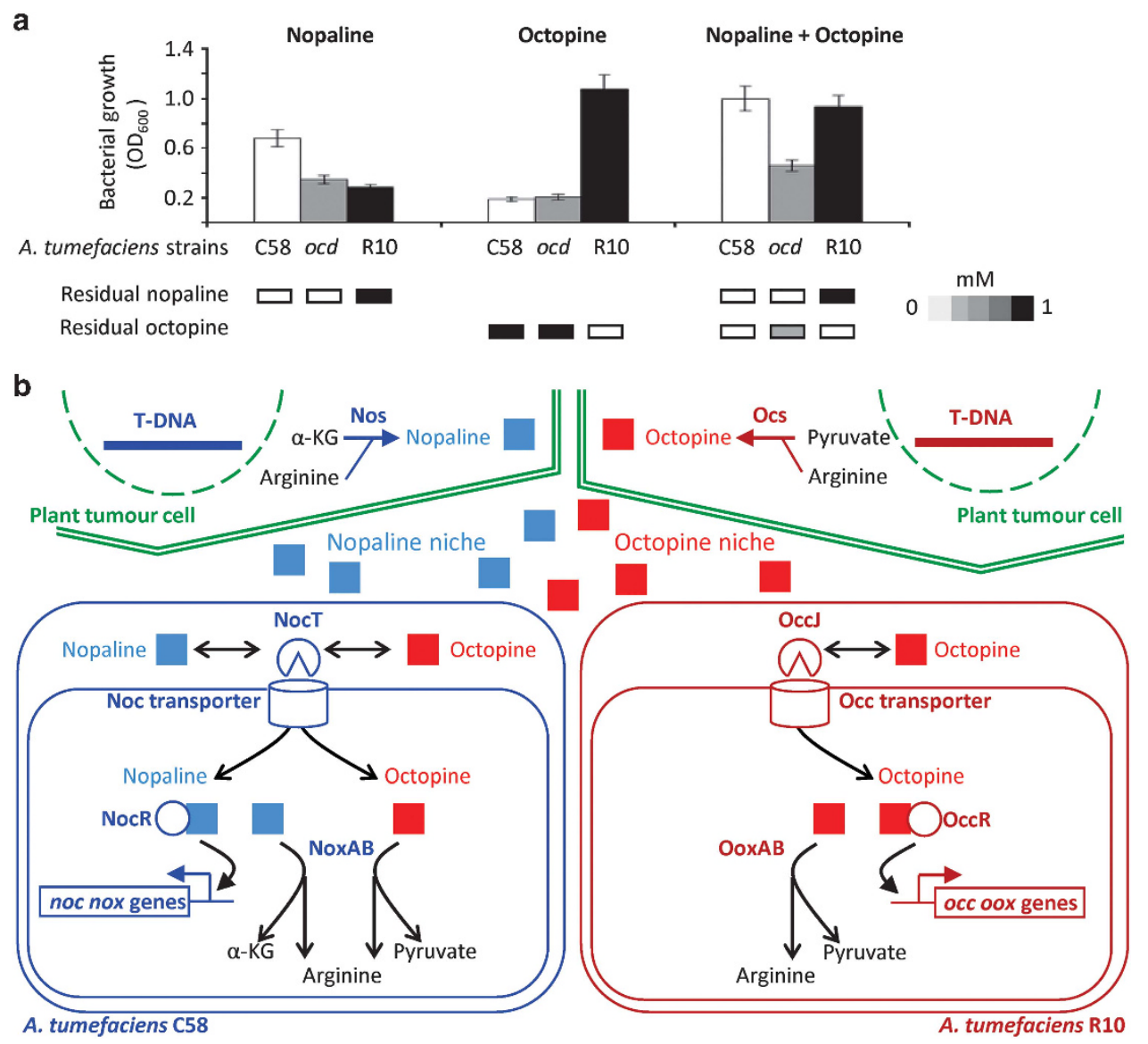

Figure 1 Assimilation of nopaline and octopine in A. tumefaciens C58 and A. tumefaciens R10. (a) The graph indicates the OD $600 n m$ of $18 \mathrm{~h}$ A. tumefaciens cultures (C58 WT, C58 ocd mutant and R10 WT backgrounds) supplemented either with nopaline or octopine or nopaline and octopine ( $1 \mathrm{~mm}$ each) as sole sources of $\mathrm{C}$ and $\mathrm{N}$ (initial $\mathrm{OD}_{600 \mathrm{~nm}}$ was 0.2 ). Below are shown the concentrations of nopaline and octopine remaining in the cultures after $18 \mathrm{~h}$. (b) Important molecular actors for the opine-niche construction (Nos and Ocs), transport (NocT and OccJ), assimilation (NoxAB and OoxAB) and gene regulation (NocR and OccR) in A. tumefaciens C58 and R10 are represented. The opine niches are constructed in the plant tumor cells through the expression of the opine synthase genes nos and ocs encoded by the T-DNA. Then, the opine niches are exploited when nopaline and octopine are imported and assimilated by A. tumefaciens that colonize the plant tumor.

electron density maps (Figure 2a). On superposition of octopine and nopaline NocT complexes, both ligands overlap making identical protein interactions for their common arginine part (Figure 2b). Interestingly, arginine alone cannot bind to NocT (Lang et al., 2014). The presence of $\alpha$-ketoglurate $(\alpha-K G)$ for nopaline and pyruvate for octopine is thus required for protein binding. The ligand binding site is composed of eight hydrophobic residues including Met117 which stabilized the pyruvate moiety of octopine by Van der Walls contacts, as previously observed for the $\alpha-K G$ in nopaline (Lang et al., 2014). In addition, we solved the structure of the NocTM117N mutant with octopine at $2.35 \AA$ resolution. This NocT mutant was previously designed to demonstrate the key-role of Met117 in nopaline affinity (Lang et al., 2014). The structure of NocTM117N in complex with octopine resembles that of wild-type NocT in complex with octopine except that the asparagine makes less contact with the ligand than the methionine (Supplementary Figure S1).
The opine-binding protein NocT displayed a similar affinity for octopine and nopaline

Fluorescence titration experiments yielded an apparent $K_{\mathrm{D}}$ value in the micromolar range with $6.1 \pm 0.7 \mu \mathrm{M}$ for NocT towards octopine (Figure 3), in the same order of magnitude than that for nopaline, $3.7 \mu \mathrm{M}$ (Lang et al., 2014). Moreover, the isothermal titration microcalorimetry data confirmed the 1:1 binding stoichiometry with a mean $K_{D}$ of $9.9 \pm 0.7 \mu \mathrm{M}$ (Figure 3). The octopine binding in NocT presented a positive enthalpy change suggesting that its binding mode is entropy driven. Remarkably, the M117N mutant displayed a $K_{\mathrm{D}}$ of $68.9 \pm 3.9 \mu \mathrm{M}$ for octopine that was seven- and tenfold higher (according to microcalorimetry and autofluorescence titrations, respectively) than that of the wild-type protein. This showed that the replacement of Met117 with Asn led to a loss of hydrophobic interactions with the ligand octopine. These affinity measurements demonstrated that the opine-trapping protein NocT does not discriminate between nopaline and octopine. 
a octopine

$$
\overbrace{\mathrm{CH}}^{\mathrm{NH}_{3}-\mathrm{CH}-\mathrm{COOH}} \mathrm{C}-\mathrm{NH}-\left(\mathrm{CH}_{2}\right)_{3}-\mathrm{CH}-\mathrm{COOH}
$$
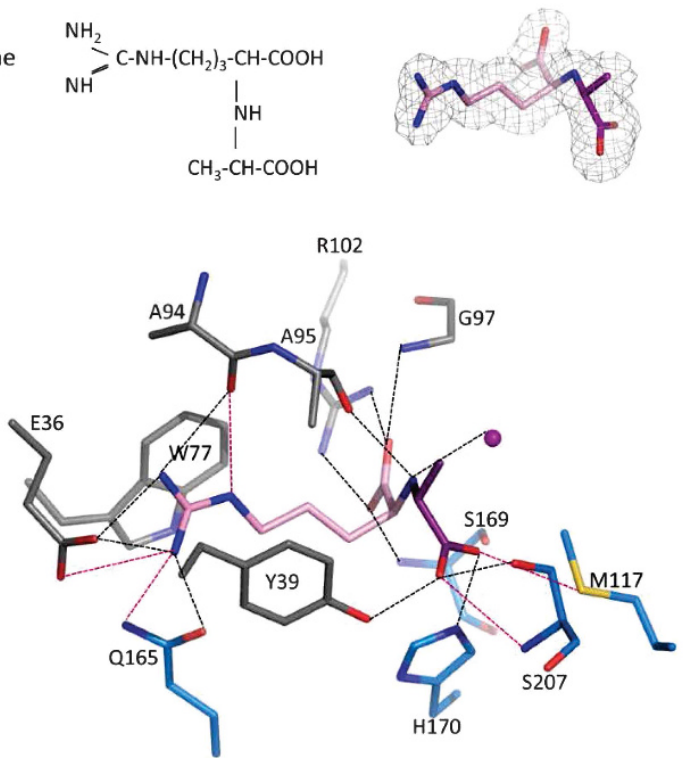

b<smiles>NC(N)NCC(CC(=O)O)NC(CC(=O)O)C(=O)O</smiles>

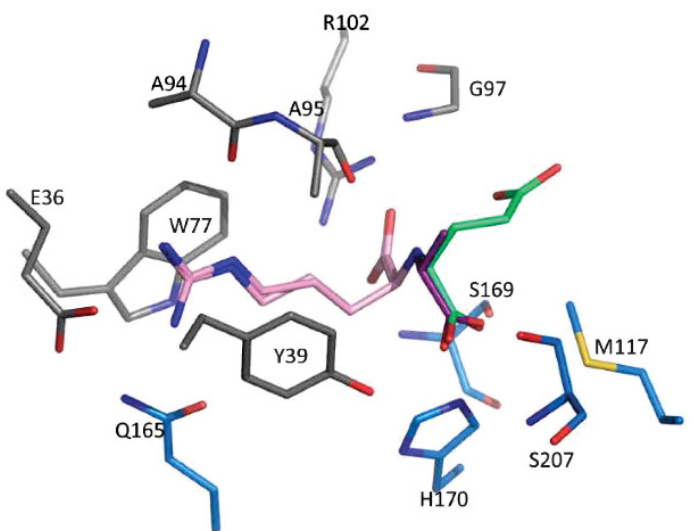

Figure 2 NocT binding site. (a) octopine bound to the ligand binding site of NocT (residues from lobe 1 are in gray, whereas residues from lobe 2 are in blue) is shown as pink/magenta for the arginine/pyruvate part, respectively, in its simulated annealing Fo-Fc omit map contoured at $4 \sigma$. Hydrogen bonds between octopine and NocT are shown as dashed lines in black for distance below $3.2 \AA$ and in magenta for distances between $3.2 \AA$ and $3.4 \AA$. (b) NocT-octopine versus NocT-nopaline. Structural comparison between the binding sites of NocT in complex with octopine (shown as pink/magenta stick) and nopaline (shown as pink/lime green stick).

Emergence of generalist users of nopaline and octopine from A. tumefaciens C58

Nopaline-type A. tumefaciens C58 requires nopaline to be able to assimilate octopine, and this requirement could constrain exploitation of the octopine niche by a nopaline-type $A$. tumefaciens if it colonizes a pre-formed octopine niche. We tested whether variants able to assimilate octopine even in the absence of nopaline can arise under the appropriate environmental conditions. After a five-day culture on agar plates containing octopine as sole source of $\mathrm{C}$ and $\mathrm{N}$, we isolated several derivatives of A. tumefaciens C58 that were able to grow on octopine even in the absence of nopaline (Figure 4a). This observation indicated the presence of genetic variation in nopaline-type $A$. tumefaciens C58 for the ability to exploit a broader niche, without induction by nopaline. This nopaline-type A. tumefaciens strain could not only assimilate octopine in addition to its specific nopaline niche, it was also able to evolve the ability to assimilate octopine in a constitutive manner. Noticeably, the reciprocal experiment in which A. tumefaciens R10 cells were plated onto a medium containing only nopaline as source of $\mathrm{C}$ and $\mathrm{N}$ yielded no nopaline-user clones, suggesting that niche expansion onto nopaline is less likely in this strain. This observation is in agreement with previous data showing that the catabolic complex NoxAB from nopaline-type bacteria can cleave both nopaline and octopine, whereas the enzymatic complex OoxAB degrades octopine only, hence limiting the possibility of a niche expansion in octopine-type bacteria (Zanker et al., 1994).
Genome scan revealed the genetic traits of derived octopine-users

We isolated 20 clones able to catabolize octopine in the absence of nopaline, 11 (oct+1 to oct+11) derived from A. tumefaciens $\mathrm{C} 58$ (pTi::Gm) and nine derived from A. tumefaciens C58 (pTi-nos::Km), which is unable to construct a nopaline niche in the plant host while retaining the capacity to import and assimilate both nopaline and octopine (Table 1). These latter nine clones permitted us to carry out in planta assays without the complication of nopaline induction and possible interpretative ambiguities resulting from nopaline and octopine interference.

Growth assay confirmed that all of the derived clones could use both octopine and nopaline as sole source of $\mathrm{C}$ and $\mathrm{N}$, unlike their ancestral strain (Figure $4 \mathrm{a}$ for a subset). The genomes of 11 of these, five derived from A. tumefaciens C58 (pTi::Gm) and six from $A$. tumefaciens C58 (pTi-nos::Km), were sequenced. Each derived strain presented between 1 and 4 nucleotide changes compared with their ancestral strain (Supplementary Table S2). Strikingly, all eleven clones displayed a nucleotide modification in the coding sequence of the nocR gene carried by the Ti-plasmid: eight at the position $40906(\mathrm{~T}>\mathrm{C})$, one at the position $40915(\mathrm{~T}>\mathrm{C})$, one at the position $40759(\mathrm{G}>\mathrm{A})$ and one at the position $41139(\mathrm{C}>\mathrm{T})$, all causing missense mutations (Figure 4a). NocR is a LysR-type transcriptional factor that controls, through binding with nopaline, the expression of the nopaline transport (noc operon) and catabolism (nox operon) genes (von Lintig et al., 1991; Figure 1b). We evaluated the expression of the 


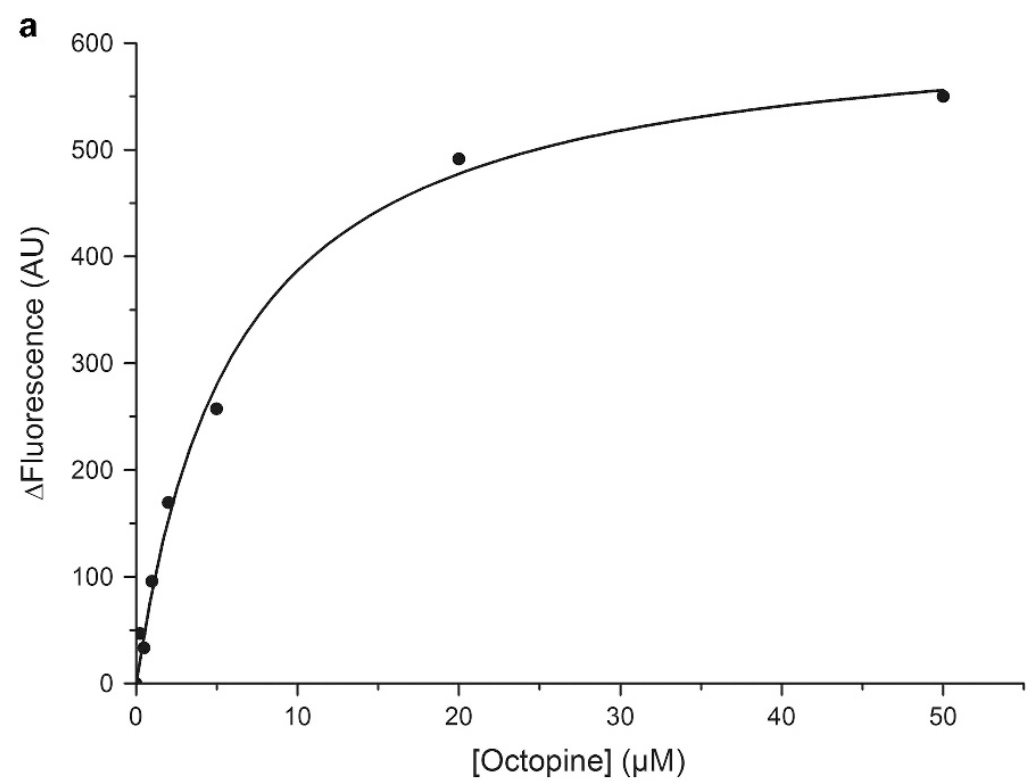

b

Time ( $\mathrm{min})$
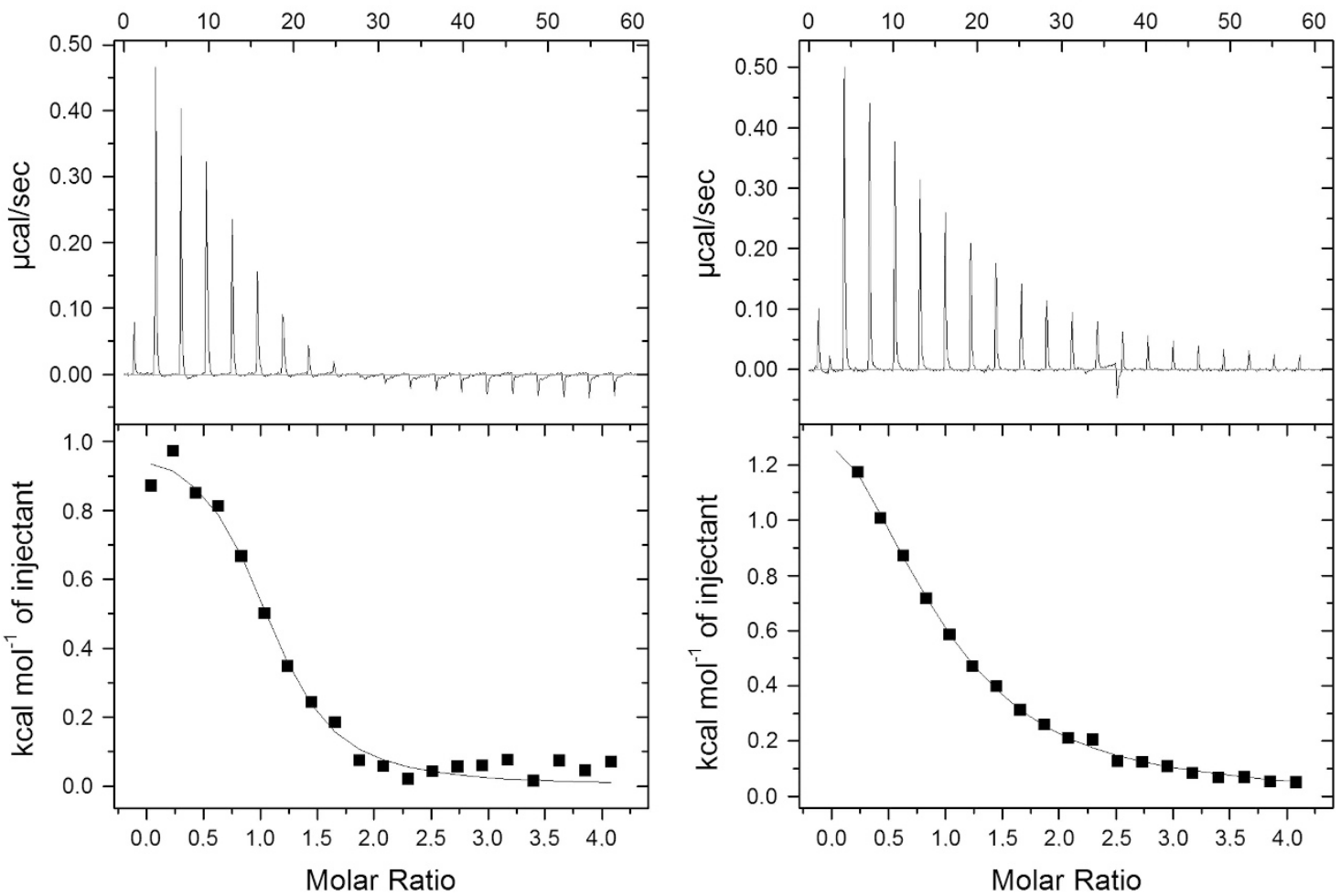

Figure 3 Fluorescence and ITC $K_{D}$ measurements. (a) wild-type NocT fluorescence monitoring on titration with octopine and fit (solid line) to a single binding model using Origin. Measures were done in triplicates. N/A: non acquired. (b) ITC measurements: The top panels show heat differences on injection of octopine with WT Noct and M117N mutant and lower panels show integrated heats of injection and the best fit (solid line) to a single binding model using Microcal Origin. Fitting values are indicated above.

noc $T$ and nox $B$ genes in octopine-users exhibiting the different variations in nocR sequence, and, compared with their ancestral strains, all exhibited from a 50 and to almost a 1000-fold increase in expression even in the absence of opines (Figure $4 \mathrm{~b}$ ).
Derived octopine-users acquired a selective advantage only in an octopine-rich plant environment

We investigated whether the octopine-users derived from nopaline-type $A$. tumefaciens might be selected in the octopine niche of a plant tumor. To be sure 

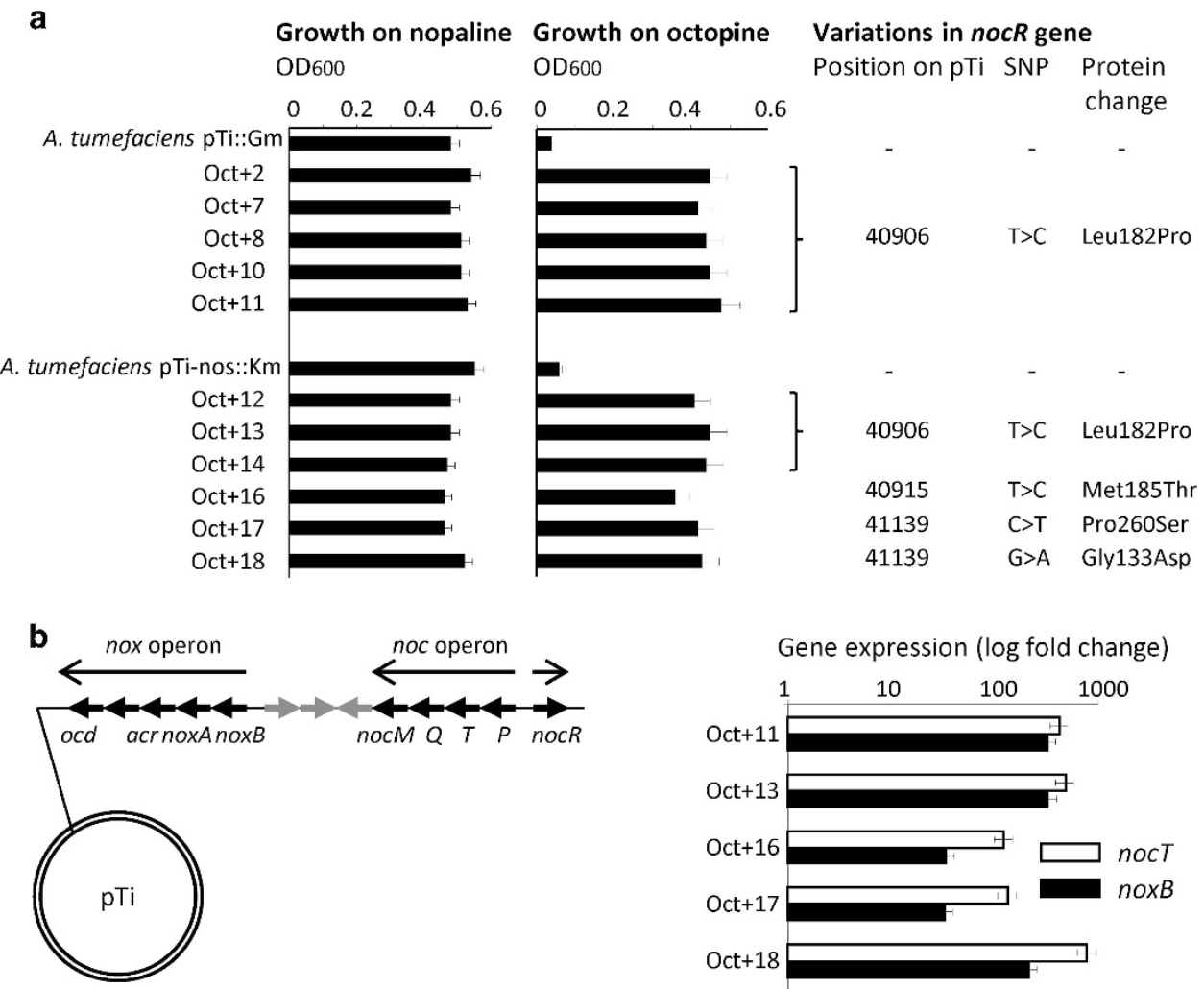

Figure 4 Characteristics of the derived octopine-users. (a) Growth of the ancestral strain and several derived strains on octopine and nopaline $\left(3 \mathrm{~mm}\right.$ ) as sole sources of carbon and nitrogen. $\mathrm{OD}_{600 \mathrm{~nm}}$ after $24 \mathrm{~h}$ in culture are shown (initial $\mathrm{OD}_{600 \mathrm{~nm}}=0.05$ ). On the right are indicated the nocR mutations carried by each variant. (b) Physical representation of the noc genes (left) and expression fold changes (Fch) of the nocT and noxB genes in different variants comparatively to the parental clones calculated by RT-qPCR (right). s.ds. were calculated from two independent experiments.

that nopaline interfering with the expression of the nopaline/octopine assimilation pathway was not produced in plant tumors, we used only A. tumefaciens C58 (pTi-nos::Km) derivatives that are unable to induce the nopaline niche. The derived octopineusers oct+13 and oct+14 were co-infected with the parental strain at approximately a 1:1 ratio in wildtype and in OCT+ A. thaliana plants, genetically modified to synthetize and accumulate octopine (Mondy et al., 2014). In all assays, the octopine contents and the proportion of competing strains were measured in plant tumors and the latter was compared with the strain proportion in the inoculum.

In octopine- and nopaline-free plant tumors induced on wild-type plants, both derived octopine-users oct +13 and oct +14 were disadvantaged in the presence of their parent (Figure 5a; Supplementary Figure S2), with a mean ( \pm s.d.) competitive index for oct+13 and oct+14 compared with their parent of only $0.33 \pm 0.17$ and $0.25 \pm 0.18$, respectively. In contrast, in the octopine-rich (about 800 pmol mg ${ }^{-1}$ of fresh plant tissue) plant environment provided by the A. thaliana OCT+ line, the derived octopine-users oct+13 and oct+14 increased their representation compared with their parent (Figure 5b), with a mean ( \pm s.d.) competitive index of $2.96 \pm 1.88$ and $3.92 \pm 2.81$, respectively. Hence, derived octopine-users may be selected in an octopine-rich environment, but they were disadvantaged in the absence of octopine and nopaline, that is, in an opine-poor environment.

Derived octopine-users were disadvantaged in A. tumefaciens R10-induced octopine-tumors

We co-inoculated wild-type $A$. thaliana plants with a triple mix (at a ratio of approximately 1:1:1) containing the $A$. tumefaciens R10 strain that induces the octopine niche, A. tumefaciens C58 (pTi-nos::Km) and a derived octopine-user (oct+13). The tumors accumulated octopine (about $200 \mathrm{pmol} \mathrm{mg}^{-1}$ of fresh plant tissue) but no nopaline (Supplementary Figure S3). Under these conditions, the proportion of the A. tumefaciens R10 compared with the two A. tumefaciens C58 strains together (derived plus ancestral strains) did not change significantly between the inoculum and the plant tumor (Fisher's exact test, $P=0.7)$. This showed that a mixed A. tumefaciens C58 population of nopalinedependent and derived, octopine-users could not outcompete $A$. tumefaciens R10 that induces and uses octopine. In the same plant tumors, when considering just the relative proportion of the two C58 strains, the derived octopine-user decreased in proportion compared with its parent between the 
a
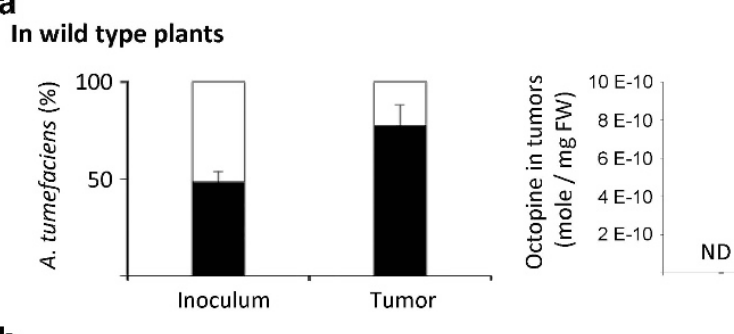

b

In octopine-producing OCT+ plants
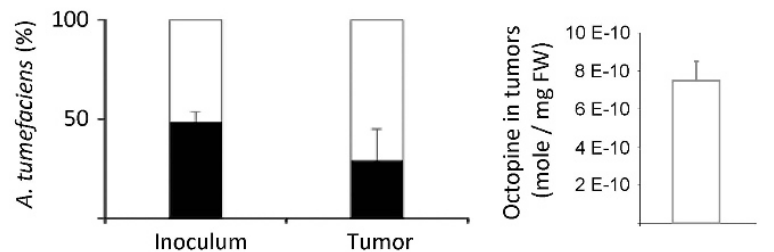

In wild type plants coinfected with $A$. tumefaciens R10

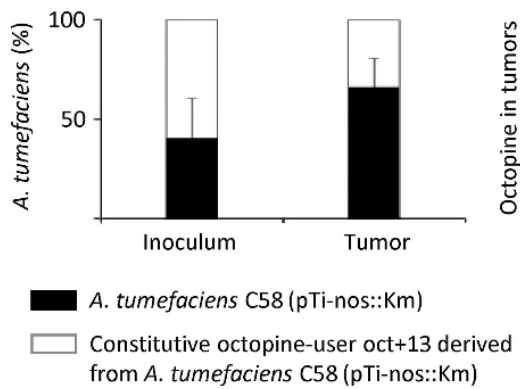

Figure 5 Fitness of a derived octopine-user versus its A. tumefaciens (pTi-nos::Km) parent in different plant tumors. (a) When inoculated into WT host plants, the ancestral $A$. tumefaciens (pTi-nos::Km) outcompeted the derived octopineuser oct+13 as shown by the significant difference in strain proportions between inoculum and tumors (Fisher's Exact test $P=1.6 \times 10^{-5}$ ). (b) When inoculated into OCT + transgenic plants, however, the derived octopine-user oct+13 outcompeted its ancestor (Fisher's Exact test $P=0.005$ ). (c) In the triple inoculation including the octopine niche-constructor and user, R10, into WT host plants, the ancestral $A$. tumefaciens (pTi-nos::Km) outcompeted the derived octopine-user oct+13 (Fisher's Exact test $P=0.04$ ). Mean and s.d. of inoculum was calculated from 3 independent samples, of tumors, from 10, 9 and 7 tumors for $\mathbf{a}, \mathbf{b}$ and c, respectively. All experiments were done on 32 days postinfection $A$. thaliana plant tumors. On the right of each graph are indicated the octopine concentrations of the analyzed tumors. s.ds were calculated from 3 independent tumors.

inoculum and the tumor (Figure 5c). The competitive index of the derived strain was only 0.5. Taken together these results established that a derived octopine-user that appears to arise easily from nopaline-type $A$. tumefaciens C58, can gain a selective advantage in an artificially high-octopine environment (Figure 5b but not in a more natural $A$. tumefaciens R10-induced octopine niche (Figure 5c). These features may explain why we do not observe cases of the expanded niche arising by natural selection in populations of nopaline-type pathogens.
Simultaneous construction of two opine-type niches affects the opine resource

The above data strongly suggested that the abundance of octopine in the plant tumor is crucial in determining the fitness cost or benefit of octopineusers derived from nopaline-type pathogens. Therefore, we investigated factors affecting opine abundance. We tested whether the simultaneous construction of two different opine-type niches in the same plant tumor could alter opine accumulation. We infected host plants with the different opine-type pathogens alone and in combination, and measured their opine content at 32 days postinfection. Supplementary Figure S3 summarizes our opine-content data. The presence of two infecting opine-type strains that induce two different opines dramatically decreased both octopine and nopaline levels compared with the tumors generated from infections of a single opine-type. Using the $A$. tumefaciens C58 (pTi-nos::Km) mutant that is defective in nopaline synthesis, we showed that the important effect arose from the induction of a second opine-niche, and not the presence of a second bacterial strain. By modifying the production and accumulation of the opine resources, two concomitant niche constructions influenced the selection regime experienced by the two coexisting pathogens. Though the generalist strategy generates an advantage under high resource levels, the low resource levels related to competing niche construction prevented the spread of a generalist mutant pathogen, thereby maintaining specialist strategies in the A. tumefaciens pathogen.

\section{Discussion}

Octopine-type and nopaline-type populations of Agrobacterium tumefaciens may co-exist in the same host plant tumors, each pathogen population being able to construct a niche in which a distinctive opine accumulates and is used as a nutrient. Surprisingly however, these two pathogen types are not equally specialized on their particular niche. Several traits allow nopaline-type pathogens to also exploit the octopine niche: (i) the opine-trapping protein NocT of the nopaline-type pathogen A. tumefaciens C58 recognized both nopaline and octopine, with a very close affinity, in the micromolar range, meaning that NocT-mediated transport system had no preference between these opines (this work); (ii) the NoxAB enzyme complex, which releases arginine from nopaline and octopine, exhibits a similar affinity and specific activity toward the two opines (Zanker et al., 1994); and (iii) when expressed, the nopaline/ octopine-assimilative pathway conferred a growth advantage to nopaline-type $A$. tumefaciens in the presence of either nopaline alone or nopaline and octopine (Figure 1). Altogether, a nopaline-type A. tumefaciens pathogen exhibits the transport and metabolic traits required to exploit an octopine niche 
in a nopaline-dependent manner. However, despite a versatile metabolism towards opines, the more generalist nopaline-type pathogen failed to outcompete the specialist octopine-type one in co-infected plant hosts, even showing a tendency to lower growth within the mixed plant tumors. Hence, hidden costs of this more generalist strategy must outweigh the apparent advantages inherent in the broader niche. Such costs of a generalist strategy are implicitly assumed in numerous models (see Palaima, 2007 for discussion) but have seldom been demonstrated (Kassen, 2002). Though we have not identified the precise nature of these costs or their mechanisms, our results suggest their existence in this system, which explains why the generalist nopaline-octopine-user does not replace the octopine specialist. Alternatively, environmental conditions within the tumor, where octopine is produced at lower concentrations than is nopaline, constrain the ability of the generalist to profit from this advantage. Indeed recent models exploring the conditions for specialist-generalist coexistence showed generalists to suffer more from competition for a rare resource than do specialists (Abrams, 2012). Though living systems seldom replicate exactly the idealized conditions of models, the A. tumefaciens strains we used reflect quite well the conditions explored in Abrams (2012) models.

Several constitutive octopine-users arose when nopaline-type strains were cultivated on octopine as sole $\mathrm{C}$ and $\mathrm{N}$ source. The novel strains arose via single nucleotide variations in the regulatory gene nocR, which permitted nopaline-independent expression of the nopaline/octopine-assimilative pathway (Supplementary Table S2), similar to the observation of Akakura and Winans (2002). We tested whether this constitutive ability to assimilate octopine could lead to a selective advantage for the derived nopaline-type $A$. tumefaciens. The constitutive variants of NocR indeed enjoyed a competitive advantage in transgenic, octopine-rich host plants that accumulated large amounts of octopine. However, competition assays in the natural octopine niche that was induced by the octopine-type pathogen revealed that the constitutive octopine-users deriving from the nopaline-type $A$. tumefaciens did not outcompete their ancestor but exhibited indeed a reduced fitness compared with the ancestral strain. This implies a cost associated with the new mutations that outweighed the advantage of niche expansion in the natural opine niche. Indeed, the mutant strains all exhibited strong, constitutive overexpression of the noc operon, which could impose a physiological cost. As a consequence, even though constitutive octopine-users might arise by de novo mutation in progeny of nopaline-type $A$. tumefaciens, they are unlikely to spread in the induced plant opine niche. This implies that the acquisition of the new ability to exploit octopine in a constitutive way, though opening new ecological opportunities for the invasion of octopine niches without needing the presence of nopaline to exploit them, imposed immediate costs that constrain the evolution of the generalist strategy (Futuyama and Moreno, 1988).

Another interesting result from our study is that tumors resulting from mixed infections of two opine types, with simultaneous construction of the octopine and nopaline niches, accumulated less opine than did tumors resulting from single infections (Supplementary Figure S3). It appears that the concomitant induction of the two opine niches affected one another. The mechanism by which this occurs remains unknown, but different parasite genotypes infecting the same host may interact in a diversity of ways, including interference or cooperation (Buckling and Brockhurst, 2008). Nopaline and octopine both require arginine as precursor for their synthesis (Figure 1b), so the two strains compete for this common substrate whose concentration in plants is tightly regulated (Winter et al., 2015). However this does not, in itself, explain why the induction of a second opine-niche should reduce the overall production of opines, unless there is some direct interference. The observation, that the simultaneous induction of two opine niches is less efficient than the induction of a single one, however, provides an additional constraint to the niche expansion process. We observed that the broader feeding niche containing more than one induced opine provided a poorer environment with lower overall resource availability. As the derived generalist octopine exploiter had a competitive advantage only at unnaturally high-octopine levels, the reduction in resource levels during co-infection will slow or prevent the spread of the generalist strategy (see also Abrams, 2012). Moreover the fact that NocT had similar affinities for nopaline and octopine suggests that the most abundant opine nopaline could be the most frequently imported. This may explain why the ability to exploit octopine in addition to nopaline granted no advantage under natural concentrations of these two opines. Altogether this work shows that niche expansion may be limited by several mechanisms, thereby explaining the maintenance of multiple specialist strategies in place of a single, generalist one (Futuyama and Moreno, 1988) in A. tumefaciens populations. Because other soil Proteobacteria such as Pseudomonas or Ensifer (Wilson et al., 1995; Oger et al., 1997; Savka and Farrand, 1997; Oger et al., 2004; Mondy et al., 2014) may exploit the opine niches that are constructed by the Agrobacterium pathogens, the question of generalist versus specialist strategy remains to be explored in these niche opportunistic populations of the plant microbiota.

\section{Conflict of Interest}

The authors declare no conflict of interest. 


\section{Acknowledgements}

JL, AV, AK, SM and DF was supported by CNRS (Mission pour l'interdisciplinarité, Agromics 2014-2016) and ANRBlanc SENSOR (ANR-12-BSV8-0003-01/02/03), and AES by a PhD-grant of the University Paris-Saclay (ED 425). This work has benefited from the I2BC plant culture facilities, I2BC high-throughput sequencing platform and I2BC crystallization platform, supported by FRISBI ANR-10-INSB-05-01. We acknowledge SOLEIL for provision of synchrotron radiation facilities (proposal ID 20130869) in using beamline Proxima I.

\section{References}

Abrams PA. (2006). The prerequisites for and likelihood of generalist-specialist coexistence. Am Nat 167: 329-342.

Abrams PA. (2012). The eco-evolutionary responses of a generalist consumer to resource competition. Evolution 66: 3130-3143.

Akakura R, Winans SC. (2002). Constitutive mutations of the OccR regulatory protein affect DNA bending in response to metabolites released from plant tumors. J Biol Chem 277: 5866-5874.

Blanc E, Roversi P, Vonrhein C, Flensburg C, Lea SM, Bricogne G. (2004). Refinement of severely incomplete structures with maximum likelihood in BUSTER-TNT. Acta Crystallogr D Biol Crystallogr 60: 2210-2221.

Bouzar H, Moore LW. (1987). Isolation of different agrobacterium biovars from a natural oak savanna and tallgrass prairie. Appl Environ Microbiol 53: 717-721.

Buckling A, Brockhurst MA. (2008). Kin selection and the evolution of virulence. Heredity 100: 484-488.

Chilton MD, Currier TC, Farrand SK, Bendich AJ, Gordon MP, Nester EW. (1974). Agrobacterium tumefaciens DNA and PS8 bacteriophage DNA not detected in crown gall tumors. Proc Natl Acad Sci USA 71: 3672-3676.

Dessaux Y, Petit A, Tempe J. (1992). Opines in Agrobacterium biology. In: Verma DPS (ed). Molecular Signals In Plant-Microbe Communications. CRC Press: Boca Raton, FL, USA, pp 109-136.

Dessaux Y, Petit A, Farrand SK, Murphy PJ. (1998). Opines and opine-like molecules involved in PlantRhizobiaceae Interactions. In: Spaink HP et al. (eds). The Rhizobiaceae, Molecular Biology of Model Plantassociated Bacteria. Kluwer Academic Publisher: Dordrecht, The Netherlands, pp 173-197.

Egas M, Dieckmann U, Sabelis MW. (2004). Evolution restricts the coexistence of specialists and generalists: The role of trade-off structure. Am Nat 163: 518-531.

Emsley P, Cowtan K. (2004). Coot: model-building tools for molecular graphics. Acta Crystallogr D Biol Crystallogr 60: $2126-2132$.

Futuyama DJ, Moreno G. (1988). The evolution of ecological specialization. Ann Rev Ecol Syst 19: 207-233.

Guyon P, Chilton MD, Petit A, Tempe J. (1980). Agropine in 'null-type' crown gall tumors: Evidence for generality of the opine concept. Proc Natl Acad Sci USA 77: 2693-2697.
Haudecoeur E, Tannières M, Cirou A, Raffoux A, Dessaux Y, Faure D. (2009). Different regulation and roles of lactonases AiiB and AttM in Agrobacterium tumefaciens C58. Mol Plant Microbe Interact 22: 529-537.

Kassen R. (2002). The experimental evolution of specialists, generalists, and the maintenance of diversity. J Evol Biol 15: 173-190.

Klapwijk PM, Oudshoorn M, Schilperoort RA. (1977). Inducible permease involved in the uptake of octopine, lysopine and octopinic acid by Agrobacterium tumefaciens strains carrying virulence-associated plasmids. Microbiology 102: 1-11.

Kylafis G, Loreau M. (2011). Niche construction in the light of niche theory. Ecol Lett 14: 82-90.

Lang J, Vigouroux A, Planamente S, El Sahili A, Blin P, Aumont-Nicaise M et al. (2014). Agrobacterium uses a unique ligand-binding mode for trapping opines and acquiring a competitive advantage in the niche construction on plant host. PLoS Pathog 10: e1004444.

Lang J, Planamente S, Mondy S, Dessaux Y, Morera S, Faure D. (2013). Concerted transfer of the virulence Ti plasmid and companion At plasmid in the Agrobacterium tumefaciens-induced plant tumour. Mol Microbiol 90: 1178-1189.

Macho AP, Guidot A, Barberis P, Beuzon CR, Genin S. (2010). A competitive index assay identifies several Ralstonia solanacearum type III effector mutant strains with reduced fitness in host plants. Mol Plant Microbe Interact 23: 1197-1205.

Mondy S, Lenglet A, Beury-Cirou A, Libanga C, Ratet P, Faure D et al. (2014). An increasing opine carbon bias in artificial exudation systems and genetically modified plant rhizospheres leads to an increasing reshaping of bacterial populations. Mol Ecol 23: 4846-4861.

Nurmi T, Parvinen K. (2008). On the evolution of specialization with a mechanistic underpinning in structured metapopulations. Theor Pop Biol 73: 222243.

Oger P, Petit A, Dessaux Y. (1997). Genetically engineered plants producing opines alter their biological environment. Nat Biotechnol 15: 369-372.

Oger PM, Mansouri H, Nesme X, Dessaux Y. (2004). Engineering root exudation of Lotus toward the production of two novel carbon compounds leads to the selection of distinct microbial populations in the rhizosphere. Microb Ecol 47: 96-103.

Palaima A. (2007). The fitness cost of generalization: present limitations and future possible solutions. Biol J Linn Soc 90: 583-590.

Pitzschke A, Hirt H. (2010). New insights into an old story: Agrobacterium-induced tumour formation in plants by plant transformation. Embo J 29: 1021-1032.

Sans N, Schroder G, Schroder J. (1987). The Noc region of Ti plasmid C58 codes for arginase and ornithine cyclodeaminase. Eur J Biochem 167: 81-87.

Satterwhite RS, Cooper TF. (2015). Constraints on adaptation of Escherichia coli to mixed-resource environments increase over time. Evolution 69: 2067-2078.

Savka MA, Farrand SK. (1997). Modification of rhizobacterial populations by engineering bacterium utilization of a novel plant-produced resource. Nat Biotechnol 15: 363-368.

Schick A, Bailey SF, Kassen R. (2015). Evolution of fitness trade-offs in locally adapted populations of Pseudomonas fluorescens. Am Nat 186: S48-S59. 
Tempé J, Petit A. (1983). La piste des opines. In: Pühler A (ed). Molecular Genetics of the Bacteria-Plant Interaction. Springer-Verlag: Berlin-Heidelberg, pp 14-32.

Tempé J. (1983). Chemistry and biochemistry of openchain imino-acids. In: Weistein B (ed). Chemistry and Biochemistry of Amino Acids, Peptides and Proteins. Marcel Dekker Inc: New York, NY, USA, pp 113-203.

Von Lintig J, Zanker H, Schroder J. (1991). Positive regulators of opine-inducible promoters in the nopaline and octopine catabolism regions of $\mathrm{Ti}$ plasmids. Mol Plant Microbe Interact 4: 370-378.

Wilson DS, Yoshimura J. (1994). On the coexistence of specialists and generalists. Am Nat 144: 692-707.

Wilson M, Savka MA, Hwang I, Farrand SK, Lindow SE. (1995). Altered epiphytic colonization of mannityl opine-producing transgenic tobacco plants by a mannityl opine-catabolizing strain of Pseudomonas syringae. Appl Environ Microbiol 61: 2151-2158.
Winter G, Todd CD, Trovato M, Forlani G, Funck D. (2015). Physiological implications of arginine metabolism in plants. Front Plant Sci 6: 534.

Wood DW, Setubal JC, Kaul R, Monks DE, Kitajima JP, Okura VK et al. (2001). The genome of the natural genetic engineer Agrobacterium tumefaciens C58. Science 294: 2317-2323.

Zanker H, Von Lintig J, Schroder J. (1992). Opine transport genes in the octopine (occ) and nopaline (noc) catabolic regions in $\mathrm{Ti}$ plasmids of Agrobacterium tumefaciens. J Bacteriol 174: 841849.

Zanker H, Lurz G, Langridge U, Langridge P, Kreusch D, Schroder J. (1994). Octopine and nopaline oxidases from $\mathrm{Ti}$ plasmids of Agrobacterium tumefaciens: molecular analysis, relationship, and functional characterization. J Bacteriol 176: 4511-4517.

Supplementary Information accompanies this paper on The ISME Journal website (http://www.nature.com/ismej) 